\title{
The suppression of kindling with low-frequency brain stimulation: Statistical data with duration variable
}

\author{
JOHN GAITO \\ York University, Downsview, Ontario, Canada
}

The use of 1- or $3-\mathrm{Hz}$ brain stimulation has been effective in eliminating or preventing kindling behavior produced by $60-\mathrm{Hz}$ stimulation. In this paper, statistical data are presented on the effects of duration of stimulation on suppressing this kindling behavior. For experimental rats, each daily experiment involved the sandwiching of the kindling-producing agent $(60-\mathrm{Hz}$ sine wave stimulation) between trials of the suppression-producing agent (1- $\mathrm{Hz}$ or $3-\mathrm{Hz}$ sine waves) (i.e., a sequence of 1-60-1 or 3-60-3). The durations used were 0 (control), 5, 15, 30, 60, 120, 180, 300 , and $600 \mathrm{sec}$. In general, the degree of suppression increased with increasing duration of stimulation. Recovery from suppression following 15 or 16 days of nonstimulation decreased with increasing durations. Complete, or near complete, recovery resulted with durations of $60 \mathrm{sec}$ or less; however, there was some recovery in all groups.

The kindling effect has been investigated in a number of laboratories (e.g., Goddard, McIntyre, \& Leech, 1969). In rats, this effect involves changes in response to electrical stimulation of a specific brain site (e.g., amygdala), from normal exploration (Stage 1), to behavioral automatisms (Stage 2: chewing, eye closure on ipsilateral side, salivation), and finally to clonic convulsions (Stage 3). During Stage 3, the rat stands on its hind paws, and bilateral convulsions of the forelimbs occur. A kindling progression occurs also in other animals: frogs, reptiles, mice, rabbits, cats, monkeys, and baboons (Racine, 1978). A permanent change that does not damage tissue is assumed to occur in the brain during kindling (Goddard et al., 1969; Racine, 1978). Behavioral, chemical, electrophysiological, and neurological aspects of this effect have been investigated by researchers (Gaito, 1976; Racine, 1978).

In a series of experiments, it was found that $1-\mathrm{Hz}$ or $3-\mathrm{Hz}$ sine wave stimulation before and after a $60-\mathrm{Hz}$ stimulation trial suppressed the tendency of the $60-\mathrm{Hz}$ current to produce kindling behavior (Gaito, 1979a, 1979b, 1980a, 1980b, 1980c, 1980d; Gaito, Nobrega, \& Gaito, 1980). The experiments with 3-Hz stimulation were conducted at an intertrial interval of $1 \mathrm{~h}$ between the imposition of the $3-\mathrm{Hz}$ and $60-\mathrm{Hz}$ stimulation trials. Other intertrial intervals have been used with the $1-\mathrm{Hz}$ agent. With 1- and 3-h intertrial intervals, the suppression effect was pronounced. The effect was present with a 24-h interval but was reduced greatly (Gaito \& Gaito, 1981); the effect was lost, or nearly lost, with 3-, 5-, and 14-day intervals (Gaito, 1982, 1984).

The author thanks Judith Emslie for calculating the means and standard deviations reported in this paper. The author's mailing address is: York University, Downsview, Ontario, Canada M3J 1P3.
In this article, statistical analyses are presented for the duration variable of the suppression effect.

\section{METHOD}

In each experiment, male Wistar rats (100-200 days of age) had nichrome bipolar electrodes placed unilaterally in the amygdala. The brain coordinates for electrode implantation were the same as in many experiments in our laboratory: $0.5 \mathrm{~mm}$ posterior to bregma, $4.5 \mathrm{~mm}$ from midline, and $8.5 \mathrm{~mm}$ from skull, using bregma as reference point.

Stimulation was not imposed until at least 7 days after surgery. On the first day, the rats were stimulated with $60-\mathrm{Hz}$ sine waves for $30 \mathrm{sec}$ during three trials, each separated by $1 \mathrm{~h}$. A Lafayette stimulator was used; the intensity was $36 \mu \mathrm{A}$ (root mean square, RMS, equivalent to $100 \mu \mathrm{A}$, peak to peak). On the first trial of the second day, the first effective threshold intensity $\left(\mathrm{ETI}_{1}\right)$ was determined. The $60-\mathrm{Hz}$ current was increased until a Stage 2 or 3 response was elicited. Then, $5 \mu \mathrm{A}$ was added to allow for day-to-day threshold fluctuations. Two further trials of stimulation at this intensity were provided to check on ETI stability. The rats were separated into two groups by pairing most rats so as to maintain approximately equal mean ETI values for the two groups.

Then, one group of rats received stimulation with $1-$ or $3-\mathrm{Hz}$ sine waves for $120 \mathrm{sec}$ on Trials 1 and 3 each day at twice the ETI $I_{1}$ value. A $60-\mathrm{Hz}$ stimulation trial was provided on Trial 2 for $30 \mathrm{sec}$ at ETI (Group 1, 1-60-1 or 3-60-3). This procedure involved a $60-\mathrm{Hz}$ stimulation trial between two $1-$ or $3-\mathrm{Hz}$ stimulation trials, with $1 \mathrm{~h}$ between trials. A second group of rats received $60-\mathrm{Hz}$ stimulation on the same trials as the first group, but on the other trials each rat was placed in the apparatus without stimulation (Group 2, X-60-X). All 60-Hz stimulation was at $\mathrm{ETI}_{1}$ for $30 \mathrm{sec}$, a duration that has been used routinely in our research. Stimulation with $1-$ or $3-\mathrm{Hz}$ current was for $120-\mathrm{sec}$ duration at two times $\mathrm{ETI}_{1}$; this duration and intensity were found in previous experiments to produce a drastic suppressive effect.

Following these 15 trials, we determined $\mathrm{ETI}_{2}$ for rats from all groups for 6 trials during 2 days ( 3 trials/day). Then we put rats through 15 trials of stimulation, in which each group was treated the same as during the block of trials leading to the $\mathrm{ETI}_{2}$ determination. This alternation of ETI determinations and blocks of trials continued through the ETI ${ }_{4}$ determination. Following a rest interval of 15 or 16 days for all rats, ETI was determined.

In these experiments, we were concerned with duration of stimulation with 1 - or $3-\mathrm{Hz}$ sine waves. Groups of rats were stimulated for 0 (control), 5, 15, 30, 60, 120,180, 300, and $600 \mathrm{sec}$. 
At the end of early experiments, histological analyses were performed on all rats. However, the electrode tips were in the amygdala in most cases. Furthermore, no gross lesions were detected at intensities of $200 \mu \mathrm{A}$ (RMS) and below, intensities that are used routinely in our experiments. The tissue surrounding the electrode tips inserted into rats stimulated with $1-\mathrm{Hz}$ or $3-\mathrm{Hz}$ and with $60-\mathrm{Hz}$ current was indistinguishable from that of rats stimulated with only $60-\mathrm{Hz}$ current. Thus, no histological analyses were conducted in later experiments.

No intensities above $200 \mu \mathrm{A}$ were used for $1-, 3-$, or $60-\mathrm{Hz}$ stimulation. Rats that showed Stage 1 behavior during an ETI determination with $60-\mathrm{Hz}$ stimulation were given a value of $208 \mu \mathrm{A}$. Thus, the upper limit for recorded ETI for any rat was $208 \mu \mathrm{A}$.

\section{RESULTS AND DISCUSSION}

The results from stimulations using $1-$ and $3-\mathrm{Hz}$ currents were similar. Thus the data for the two frequencies were combined. The means for durations from $0-600 \mathrm{sec}$ are presented in Table 1. The standard deviations, in Table 2 , do not indicate any systematic trends. As with many data, there is a tendency for larger standard deviations to occur with greater means. Some of the data in Table 2 show the opposite result. For example, low or zero values for $\mathrm{ETI}_{3}$ and $\mathrm{ETI}_{4}$ with the groups enduring stimulations of $120 \mathrm{sec}$ and greater are due to the fact that many of these rats showed a Stage 1 response and consistently received a value of $208 \mu \mathrm{A}$.

From data in Table 1, we see a number of significant points on effects of and recovery from suppression.

\section{Suppression Effect}

(1) The control $(0-\mathrm{sec})$ group shows the gradual mean decrease over ETI determinations which is typical of the control group.

(2) The 5-sec group also has a slight decrement over the determinations; however, the decrement is less than

Table 1

Mean ETI Values and ETI/ETI ${ }_{1}$ Ratios for Various Durations (in Seconds) of 1- and 3-Hz Brain Stimulation

\begin{tabular}{ccccccc}
\hline & & \multicolumn{5}{c}{ ETI Determinations } \\
\cline { 3 - 7 } Duration & $\mathrm{n}$ & 1 & 2 & 3 & 4 & 5 \\
\hline $0^{*}$ & 18 & 105.0 & 76.3 & 58.2 & 52.1 & 44.6 \\
& & 1.00 & .727 & .554 & .496 & .425 \\
5 & 15 & 99.4 & 91.6 & 87.6 & 80.6 & 75.3 \\
& & 1.00 & .922 & .881 & .811 & .758 \\
15 & 6 & 50.8 & 66.7 & 73.3 & 95.8 & 51.5 \\
& & 1.00 & 1.31 & 1.44 & 1.89 & 1.01 \\
30 & 15 & 69.0 & 102.1 & 123.9 & 134.8 & 69.2 \\
& & 1.00 & 1.48 & 1.80 & 1.95 & 1.00 \\
60 & 12 & 68.9 & 114.4 & 163.8 & 176.6 & 74.4 \\
& & 1.00 & 1.66 & 2.38 & 2.56 & 1.08 \\
120 & 13 & 68.3 & 155.8 & 201.3 & 203.2 & 86.9 \\
& & 1.00 & 2.28 & 2.95 & 2.98 & 1.27 \\
180 & 6 & 103.0 & 164.7 & 204.0 & 206.7 & 110.8 \\
& & 1.00 & 1.60 & 1.98 & 2.01 & 1.08 \\
300 & 14 & 66.4 & 199.1 & 208.0 & 208.0 & 172.6 \\
& & 1.00 & 3.00 & 3.13 & 3.13 & 2.60 \\
600 & 8 & 67.0 & 173.1 & 208.0 & 208.0 & 151.0 \\
& & 1.00 & 2.58 & 3.10 & 3.10 & 2.25 \\
\hline
\end{tabular}

Note-For each duration, the upper numbers in a set are the mean ETI values. The lower numbers are the ETI/ETI $I_{1}$ ratios. ${ }^{*}$ Control group.
Table 2

Standard Deviations for Various Durations (in Seconds) of 1- and 3-Hz and Brain Stimulation

\begin{tabular}{cccccc}
\hline & \multicolumn{5}{c}{ ETI Determinations } \\
\cline { 2 - 6 } Duration & 1 & 2 & 3 & 4 & 5 \\
\hline 0 & 65.6 & 37.3 & 29.6 & 26.8 & 23.8 \\
5 & 66.0 & 60.8 & 60.1 & 57.6 & 58.7 \\
15 & 17.2 & 29.1 & 28.0 & 32.9 & 13.5 \\
30 & 46.8 & 67.0 & 62.1 & 61.0 & 33.9 \\
60 & 39.7 & 60.3 & 48.4 & 43.5 & 38.6 \\
120 & 36.6 & 58.7 & 12.9 & 11.9 & 33.1 \\
180 & 53.3 & 48.1 & 4.4 & 3.3 & 25.4 \\
300 & 55.7 & 13.5 & 0 & 0 & 59.4 \\
600 & 58.1 & 50.8 & 0 & 0 & 41.5 \\
\hline
\end{tabular}

Note- $n$ is same as in Table 1.

that for the control group. The discrepancy between the two groups is shown clearly by taking the ratio of each ETI determination to that value on $\mathrm{ETI}_{1}$. This ratio drops quickly for the control group, and for the fifth ETI determination it is well below half. The decrement for the 5sec group goes from $1.00\left(\mathrm{ETI}_{1}\right)$ to .758 at the $\mathrm{ETI}_{5}$ determination.

(3) The 15-, 30-, and 60-sec stimulations provide moderate effects. The value of the ratio $\mathrm{ETI}_{4} / \mathrm{ETI}_{1}$ goes from 1.89 and 1.95 for 15 - and $30-\mathrm{sec}$ stimulations to 2.56 for 60 -sec stimulation. The $\mathrm{ETI}_{4}$ determination is the final one after $1-$ or $3-\mathrm{Hz}$ stimulation trials.

(4) The 120-sec group shows a great suppression effect. Furthermore, the mean ETI values for the third and fourth determinations are lower than they might have been. We do not stimulate at intensities above $200 \mu \mathrm{A}$. A Stage 1 response at this level is recorded at $208 \mu \mathrm{A}$. Thus, the effect could be more pronounced than the data suggests.

(5) Stimulation at 300 and $600 \mathrm{sec}$ produces a drastic effect by the $\mathrm{ETI}_{2}$ determination. A number of rats show a Stage 1 response at $\mathrm{ETI}_{2}$.

(6) There is a gradual increase in the suppression effect from $5 \mathrm{sec}$ to $600 \mathrm{sec}$. However, the 180 -sec stimulation group provides an exception to this trend. The ratio values for this group are more like the 60 -sec group than like the 120 -sec group. This fact may be due to the high mean value of 103.0 at ETI $_{1}$ for the 180 -sec group. This mean is much greater than that for most of the groups. Furthermore, there are only six rats in this group; thus, this mean is less reliable than are most of the other means.

\section{Recovery from Suppression}

After the fourth ETI determination, there was a rest from stimulation for 15 or 16 days. Thus, the ratio of $\mathrm{ETI}_{5} / \mathrm{ETI}_{1}$ provides an indication of the possibility of recovery of the animal from the suppression tendency. From this analysis, a number of important points occur. (1) The control and 5-sec groups have ratios less than 1.00. (2) The groups for 15-, 30-, and 60-sec stimulation show ratios of approximately 1.00 , indicating a return to $\mathrm{ETI}_{1}$ values. (3) The 120 -sec group shows recovery 
Table 3

ETI Ratio Comparisons

\begin{tabular}{cccc}
\hline & \multicolumn{3}{c}{ Ratios } \\
\cline { 2 - 4 } Duration & $2-1^{*}$ & $4-1^{* *}$ & $5-1 \dagger$ \\
\hline 0 & -.273 & -.504 & -.575 \\
5 & -.078 & -.189 & -.242 \\
15 & .31 & .89 & .001 \\
30 & .48 & .95 & .000 \\
60 & .66 & 1.56 & .080 \\
120 & 1.28 & 1.98 & .27 \\
180 & .60 & 1.01 & .080 \\
300 & 2.00 & 2.13 & 1.60 \\
600 & 1.58 & 2.10 & 1.25 \\
\hline
\end{tabular}

Note-Duration given in seconds. ${ }^{*} E T I_{2} / E T I_{1}$ minus 1.00 .

${ }^{* *} E T I_{4} / E T I_{1}$ minus 1.00 . $\dagger E T I_{5} / E T I_{1}$ minus 1.00 .

Table 4

Summary Sheet for Means of $\mathbf{1 - H z}$ and 3-Hz Stimulation Effects Relative to Durations

\begin{tabular}{rll}
\hline Duration & Suppression* & \multicolumn{1}{c}{ Recovery** } \\
\hline 0 & not relevant & not relevant \\
5 & minimal & complete \\
15 & modest & complete or nearly complete \\
30 & modest & complete or nearly complete \\
60 & modest & complete or nearly complete \\
120 & great effect & almost complete, but a slight effect remains \\
180 & great $\dagger$ & complete or nearly complete \\
300 & drastic & little recovery \\
600 & drastic & little recovery \\
\hline
\end{tabular}

*Determined by the value of ETI $-E T I_{1} . \quad$ **Determined by the value of $E T I_{5}-E T I_{1} . \quad \dagger$ This is expected result. However, see discussion in text.

from suppression, but less than that for lower duration groups. (4) The 300 - and 600 -sec groups show little recovery. (5) The results for the 180 -sec group do not follow the trend of decreased recovery with increasing duration of stimulation. However, this may result from the high $\mathrm{ETI}_{1}$ determination (compared to other groups). (6) All groups from $15 \mathrm{sec}$ and above had a substantial drop in the ratio of $\mathrm{ETI}_{5} / \mathrm{ETI}_{1}$ as compared to the ratio of $\mathrm{ETI}_{4} / \mathrm{ETI}_{1}$. Thus, the rest period was effective in allowing all or part of the suppression tendency to dissipate.

These effects are shown clearly in Table 3, which provides comparisons of the ratio relative to specific ETI determinations for the various durations, and in Table 4, which provides a summary. The $\mathrm{ETI}_{2} / \mathrm{ETI}_{1}$ ratio minus the $\mathrm{ETI}_{1} / \mathrm{ETI}_{1}$ ratio (1.00) indicates the magnitude of the short term suppression tendency, whereas the 4-1 comparison shows a longer term suppression effect. These two measures are suppression indices: Positive values indicate suppression, with increasing degree related to increasing magnitudes. The 5-1 comparison indicates the recovery from suppression, a recovery index. Values of zero or below indicate lack of residual suppression (i.e., complete, or near complete, recovery); positive values indicate incomplete recovery, with higher values indicating less recovery.

\section{REFERENCES}

GaIto, J. (1976). The kindling effect as a model of epilepsy. Psychological Bulletin, 83, 1097-1109.

GAITO, J. (1979a). 3-Hz brain stimulation interferes with various aspects of the kindling effect. Bulletin of the Psychonomic Society, 13, 67-70.

GaITo, J. (1979b). Suppression of 60-Hz-induced convulsive behavior by $3-\mathrm{Hz}$ brain stimulation. Bulletin of the Psychonomic Society, 13, 223-226.

GaITo, J. (1980a). The effect of variable duration one hertz interference on kindling. Canadian Journal of Neurological Sciences, 7, 59-64.

GaITo, J. (1980b). The effect of varying durations of stimulation on the 3-Hz interference effect. Bulletin of the Psychonomic Society, 15, 211-214.

GaITo, J. (1980c). Gradient of interference by various frequencies on $60-\mathrm{Hz}$ kindled behavior. Canadian Journal of Neurological Sciences, 7, 223-226.

GAITo, J. (1980d). Interference effects within the kindling paradigm. Physiological Psychology, 8, 120-125.

GaITo, J. (1982). The effect of a 72-h intertrial interval on the 1-Hz suppression effect in rats. Bulletin of the Psychonomic Society, 19, 362-364.

GaITo, J. (1984). The effect of 5- and 14-day intertrial intervals on the 1-Hz suppression effect. Bulletin of the Psychonomic Society, 23, 474-476.

GaIto, J., \& GaITo, S. T. (1981). The effect of several intertrial intervals on the 1-Hz interference effect. Canadian Journal of Neurological Sciences, 8, 61-65.

Gaito, J., Nobrega, J. N., \& Gaito, S. T. (1980). The interference effect of $3-\mathrm{Hz}$ brain stimulation on kindling behavior induced by $60-$ $\mathrm{Hz}$ stimulation. Epilepsia, 21, 73-84.

Goddard, G. V., McInTyRe, D. C., \& Leech, C. K. (1969). A permanent change in brain function resulting from daily electrical stimulation. Experimental Neurology, 25, 295-330.

Racine, R. J. (1978). Kindling: The first decade. Neurosurgery, 3, 234-252.

(Manuscript received for publication March 18, 1985.) 